\title{
Genetic Diversity and Association Analysis for Solvent Retention Capacity in the Accessions Derived from Soft Wheat Ningmai 9
}

\author{
Peng Jiang, Ping-Ping Zhang, Xu Zhang, and Hong-Xiang Ma \\ Provincial Key Lab for Agrobiology, Jiangsu Academy of Agricultural Sciences/Jiangsu Collaborative Innovation Center for \\ Modern Crop Production, 50 Zhongling Street, Nanjing, Jiangsu 210014, China
}

Correspondence should be addressed to Hong-Xiang Ma; hxma@jaas.ac.cn

Received 2 August 2016; Revised 14 October 2016; Accepted 16 January 2017; Published 5 February 2017

Academic Editor: Mihai Miclăuş

Copyright (C) 2017 Peng Jiang et al. This is an open access article distributed under the Creative Commons Attribution License, which permits unrestricted use, distribution, and reproduction in any medium, provided the original work is properly cited.

\begin{abstract}
Solvent retention capacity (SRC) test is an effective method for quality evaluation of soft wheat. Ningmai 9 is a founder in soft wheat breeding. The SRC and genotype of Ningmai 9 and its 117 derivatives were tested. Association mapping was employed to identify the quantitative trait loci (QTL) associated with SRCs. Ningmai 9 had the allele frequency of $75.60 \%$ and $67.81 \%$ to its first- and second-generation derivatives, respectively, indicating higher contribution than theoretical expectation. Neighbor-joining cluster based on the genotyping data showed that Ningmai 9 and most of its first-generation derivatives were clustered together, whereas its second-generation derivatives were found in another group. The variation coefficients of SRCs in the derivatives ranged from $5.35 \%$ to $8.63 \%$. A total of 29 markers on 13 chromosomes of the genome were associated with the SRCs. There were 6 markers associated with more than one SRC or detected in two years. The results suggested that QTL controlling SRCs in Ningmai 9 might be different from other varieties. Markers Xgwm44, Xbarc126, Xwmc790, and Xgwm232 associated with SRCs in Ningmai 9 might be used for quality improvement in soft wheat breeding.
\end{abstract}

\section{Introduction}

Soft wheat flour of low protein content is usually associated with the cookie quality [1], which produces good quality cookies with a large spread factor, such as low thickness, tender texture with smaller particle size, and low water absorption. Soft wheat yields less flour with a smaller average particle size and less damaged starch [2].

In comparing with hard wheat, solvent retention capacity (SRC) is used more often for evaluating the quality of soft wheat in cookie making [3]. SRC is the weight of solvent held by flour after centrifugation and draining. SRC tests were developed by Slade and Levine (1994) to estimate grain and end-use quality in soft wheat [4]. They are all based on a mixture of flour plus one of four different solutions: water, $5 \%$ sodium carbonate $\left(\mathrm{NaCO}_{3}\right), 5 \%$ lactic acid, and $50 \%$ sucrose to predict water-holding capacity, damaged starch, gluten strength, and water soluble pentosan (arabinoxylan), respectively [3]. SRC was mainly determined by genotype [5-7]; however, most of the previous studies concerned the evaluation of SRC in different genotypes with various treatments, whereas the genetic mechanism of SRC received little attention.

Understanding genetic mechanisms and the identification of quantitative trait loci (QTL) associated with the components regulating end-use traits are the basis for quality improvement in wheat. Several mapping studies have been conducted to locate QTL associated with baking quality in wheat. However, most of them were conducted using hard wheat population. In soft wheat, Smith et al. (2011) reported large effect QTL for quality on chromosomes $1 \mathrm{~B}$ and 2B [8]. Cabrera et al. (2015) identified 26 regions as potential QTL in a diversity panel and 74 QTL in all 5 biparental mapping populations [9].

Association mapping is a method to test the association between molecular markers and QTL based on linkage disequilibrium [10]. In recent years, it has been widely used for QTL detection in main crops, such as maize, wheat, and rice [11-13]. Generally, natural populations with wide genetic basis were used for association mapping $[14,15]$. In soft wheat, Cabrera et al. (2015) identified 26 regions as potential QTL in a diversity panel from the soft wheat breeding program in 
USA by using an association mapping approach [9]. Zhang et al. (2015) discovered several favorable allelic variations for SRCs by association mapping with a natural population including 176 varieties (lines) from China [16].

Association mapping on founder parents and its derivatives can find some important QTL and favorable allelic variations in founder parent, which can be further used for marker assisted selection to produce more favorable varieties [17]. Ningmai 9 is a soft wheat cultivar with desirable quality and has been widely used in wheat production and as parent in the Yangtze River to Huai River valley area in China. A total of 20 cultivars derived from Ningmai 9 have been released in the past 10 years. Ningmai 9 has high general combining ability in SRCs [18]; however, the QTL and chromosome regions associated with SRCs in Ningmai 9 were unclear. In this study, the genotypes of Ningmai 9 and its derivatives were screened with SSR molecular markers covering wholegenome; meanwhile the phenotypes of SRCs were analyzed in two consecutive growth seasons. The genetic structure, genetic similarity, and association mapping were analyzed to reveal the relationship between Ningmai 9 and its derivatives and to identify molecular markers associated with SRCs.

\section{Materials and Methods}

2.1. Plant Materials and Phenotyping. Ningmai 9 and its 117 derivatives including 39 lines of first generation and 78 lines of second generation were used in this study (Table 1). The materials were planted in 2014 and 2015 at the experimental farm of Jiangsu Academy of Agricultural Sciences in Nanjing, China. Each line was planted in a plot comprising 3 rows with two replications. Each row was sowed with 50 seeds with the length of $1.3 \mathrm{~m}$ and a row-to-row distance of $0.25 \mathrm{~m}$. After harvest and milling, the flour was tested for SRCs according to AACC 56-11 $[19,20]$. The SRC of water, sodium carbonate, lactic acid, and sucrose were described as WSRC, SCSRC, LaSRC, and SuSRC, respectively.

2.2. Genotype Analysis. DNA was extracted from fresh leaves using a CTAB procedure according to Saghai-Maroof et al. (1984) [21]. One hundred and eighty-five polymorphic simple sequence repeat (SSR) primer pairs were used to screen Ningmai 9 and its 117 derived lines in the study. These markers were randomly distributed across the wheat genome, and each chromosome included 5-14 markers with an average of 8.8 markers. Map positions of markers were based on the linkage map reported by Somers et al. (2004) [22].

Each $10 \mu \mathrm{L}$ PCR contained $1 \mu \mathrm{L} 10 \times$ PCR buffer, $0.6 \mu \mathrm{L}$ $15 \mathrm{mM} \mathrm{MgCl}_{2}, 0.8 \mu \mathrm{L} 2 \mathrm{mMdNTP}, 1 \mu \mathrm{L} 0.02 \mu \mathrm{M}$ of each primer, $0.1 \mu \mathrm{LTaq}$ DNA polymerase, $1 \mu \mathrm{L} 0.02 \mu \mathrm{M}$ template DNA, and $3.5 \mu \mathrm{L}$ deionized water. The cycling system consisted of an initial denaturation step of $94^{\circ} \mathrm{C} / 5 \mathrm{~min}$, followed by 36 cycles of $94^{\circ} \mathrm{C} / 45 \mathrm{~s}, 50 \sim 60^{\circ} \mathrm{C} / 45 \mathrm{~s}, 72^{\circ} \mathrm{C} / 60 \mathrm{~s}$, and a final extension of $72^{\circ} \mathrm{C} / 10 \mathrm{~min}$. Amplification bands were electrophoretically separated through nondenaturating $6 \%$ polyacrylamide gels and visualized by silver staining.

2.3. Data Processing and Analysis. Excel 2007 was used for data preparation; ANOVA was performed using SPSS 17.0.
TABLE 1: List of Ningmai 9 and its derivatives.

\begin{tabular}{|c|c|c|}
\hline Generation & Number & Variety/lines \\
\hline Parent & L1 & Ningmai 9 \\
\hline \multirow{50}{*}{ 1st generation } & L2 & Ningmai 13 \\
\hline & L3 & Ningmai 14 \\
\hline & L4 & Ningmai 16 \\
\hline & L5 & Shengxuan 6 \\
\hline & L6 & Yangmai 18 \\
\hline & L7 & Yangfumai 4 \\
\hline & L8 & $3 \mathrm{E} / 158$ \\
\hline & L9 & Nannong 0686 \\
\hline & L10 & Ningmai 18 \\
\hline & L11 & Ning 0556 \\
\hline & L12 & Ning 07123 \\
\hline & L13 & Ning 07119 \\
\hline & L14 & Ning 0853 \\
\hline & L15 & Ning 0866 \\
\hline & L16 & Ning 0894 \\
\hline & L17 & Ning 08105 \\
\hline & L18 & Ning 0561 \\
\hline & L19 & Ning 0564 \\
\hline & L20 & Ning 0565 \\
\hline & L21 & Ning 0417 \\
\hline & L22 & Ning 0418 \\
\hline & L23 & Ning 0422 \\
\hline & L24 & Ning 0311 \\
\hline & L25 & Ning 0316 \\
\hline & L26 & Ning 0319 \\
\hline & L27 & Ning 0320 \\
\hline & L28 & Ning 0327 \\
\hline & L29 & Ning 0331 \\
\hline & L35 & Ning 9-11 \\
\hline & L36 & Ning 9-36 \\
\hline & L37 & Ning 9 Large 41 \\
\hline & L38 & Ning 9 Large 44 \\
\hline & L39 & Ning 9 Large 76 \\
\hline & $\mathrm{L} 40$ & Ning 9 Large 78 \\
\hline & L41 & Ning 9 Large 80 \\
\hline & L60 & 71666 \\
\hline & L61 & $6 \mathrm{E} / 123$ \\
\hline & L62 & $09-654$ \\
\hline & L64 & $09-444$ \\
\hline & L30 & Ning 0798 \\
\hline & L31 & Ning 07117 \\
\hline & L32 & F307 \\
\hline & L33 & F308 \\
\hline & L34 & Ning 0797 \\
\hline & $\mathrm{L} 42$ & Ning 0862 \\
\hline & L43 & Ning 0869 \\
\hline & L44 & Ning 0872 \\
\hline & L45 & Ning 0880 \\
\hline & L46 & Ning 0882 \\
\hline & L47 & Ning 0884 \\
\hline
\end{tabular}


TABle 1: Continued.

\begin{tabular}{|c|c|c|}
\hline Generation & Number & Variety/lines \\
\hline \multirow{52}{*}{ 2nd generation } & L48 & Ning 0887 \\
\hline & L49 & Ning 0893 \\
\hline & L50 & Ning 0895 \\
\hline & L51 & Ning 0897 \\
\hline & L52 & Ning 0898 \\
\hline & L53 & Ning 0899 \\
\hline & L54 & Ning 08102 \\
\hline & L55 & Ning 08104 \\
\hline & L56 & Ning 08108 \\
\hline & L57 & Ning 08110 \\
\hline & L58 & Ning 08115 \\
\hline & L59 & Ning 08116 \\
\hline & L63 & 09-569 \\
\hline & L65 & Zhenmai 166 \\
\hline & L66 & Ning 0867 \\
\hline & L67 & Ning 0881 \\
\hline & L68 & Ning 0883 \\
\hline & L69 & Ning 0886 \\
\hline & L70 & Ning 0896 \\
\hline & L71 & Ning 08109 \\
\hline & L72 & Ning 08111 \\
\hline & L73 & Ning 08112 \\
\hline & L74 & Ning 08113 \\
\hline & L75 & 08F331 \\
\hline & L76 & 08F333 \\
\hline & L77 & 08F337 \\
\hline & L78 & 08F353 \\
\hline & L79 & 08F362 \\
\hline & L80 & 08F386 \\
\hline & L81 & 08F387 \\
\hline & L82 & 08F396 \\
\hline & L83 & 08F397 \\
\hline & L84 & 08F399 \\
\hline & L85 & 08F406 \\
\hline & L86 & 08F407 \\
\hline & L87 & 08F408 \\
\hline & L88 & 08F409 \\
\hline & L89 & 08F410 \\
\hline & L90 & 08F411 \\
\hline & L91 & $08 \mathrm{~F} 417$ \\
\hline & L92 & 08F418 \\
\hline & L93 & $08 \mathrm{~F} 423$ \\
\hline & L94 & 08F424 \\
\hline & L95 & 08F426 \\
\hline & L96 & 08F432 \\
\hline & L97 & 08F433 \\
\hline & L98 & 08F434 \\
\hline & L99 & 08F435 \\
\hline & L100 & 08F436 \\
\hline & L101 & 08F437 \\
\hline & L102 & 08F442 \\
\hline & L103 & $08 \mathrm{~F} 443$ \\
\hline
\end{tabular}

TABle 1: Continued.

\begin{tabular}{|c|c|c|}
\hline Generation & Number & Variety/lines \\
\hline & L104 & 08F444 \\
\hline & L105 & $08 \mathrm{~F} 445$ \\
\hline & L106 & 08F446 \\
\hline & L107 & 08F448 \\
\hline & L108 & 08F449 \\
\hline & L109 & 08F450 \\
\hline & L110 & $08 \mathrm{~F} 451$ \\
\hline & L111 & 08F453 \\
\hline & L112 & 08F454 \\
\hline & L113 & 08F457 \\
\hline & L114 & 08F458 \\
\hline & L115 & 08F468 \\
\hline & L116 & 08F459 \\
\hline & L117 & 08F516 \\
\hline & L118 & 08F517 \\
\hline
\end{tabular}

Neighbor-joining cluster was performed with Mega 6.0 [23]. Both the $Q$ matrix and $K$ matrix were determined using STRUCTURE v2.3.4 [24]. Five independent simulations were processed for each $k$, ranging from 1 to 8 , with a 10,000 burnin length and 100,000 iterations. The association analysis was calculated using the mixed linear model (MLM) method incorporated into the TASSEL 3.0 software [25]. The significant marker-trait associations were declared for $P \leq 0.01$.

\section{Results}

3.1. Genetic Contribution of Ningmai 9 to Its Derivatives. A total of 490 alleles were detected with 1-7 and an average of 2.6 alleles per locus. The ratio of allele frequency between Ningmai 9 and its derivatives on the chromosomes ranged from $55.71 \%$ to $88.29 \%$ with an average of $75.60 \%$ for first generation and from $56.33 \%$ to $83.50 \%$ with an average of $67.81 \%$ for second generation (Table 2), which indicated that Ningmai 9 had a higher contribution to its derivatives than theoretically expected. Both first and second generation had highest allele frequency on chromosome 4A. The first generation possesses the higher allele frequency compared to the second on all chromosomes except for chromosome 6D.

3.2. Population Structure Analysis and Cluster Analysis. In order to eliminate the spurious association caused by population structure of the materials, the number of populations was calculated according to the method by Evanno et al. (2005) [26]. Two populations in the materials were previously reported in our research [27].

Neighbor-joining cluster based on the genotyping data also showed that there were 2 groups in the materials (Figure 1). Ningmai 9 and most of its first-generation derivatives were clustered together, whereas its second-generation derivatives were found in another group. Yangfumai 4 was distantly clustered with those two groups since it was a 


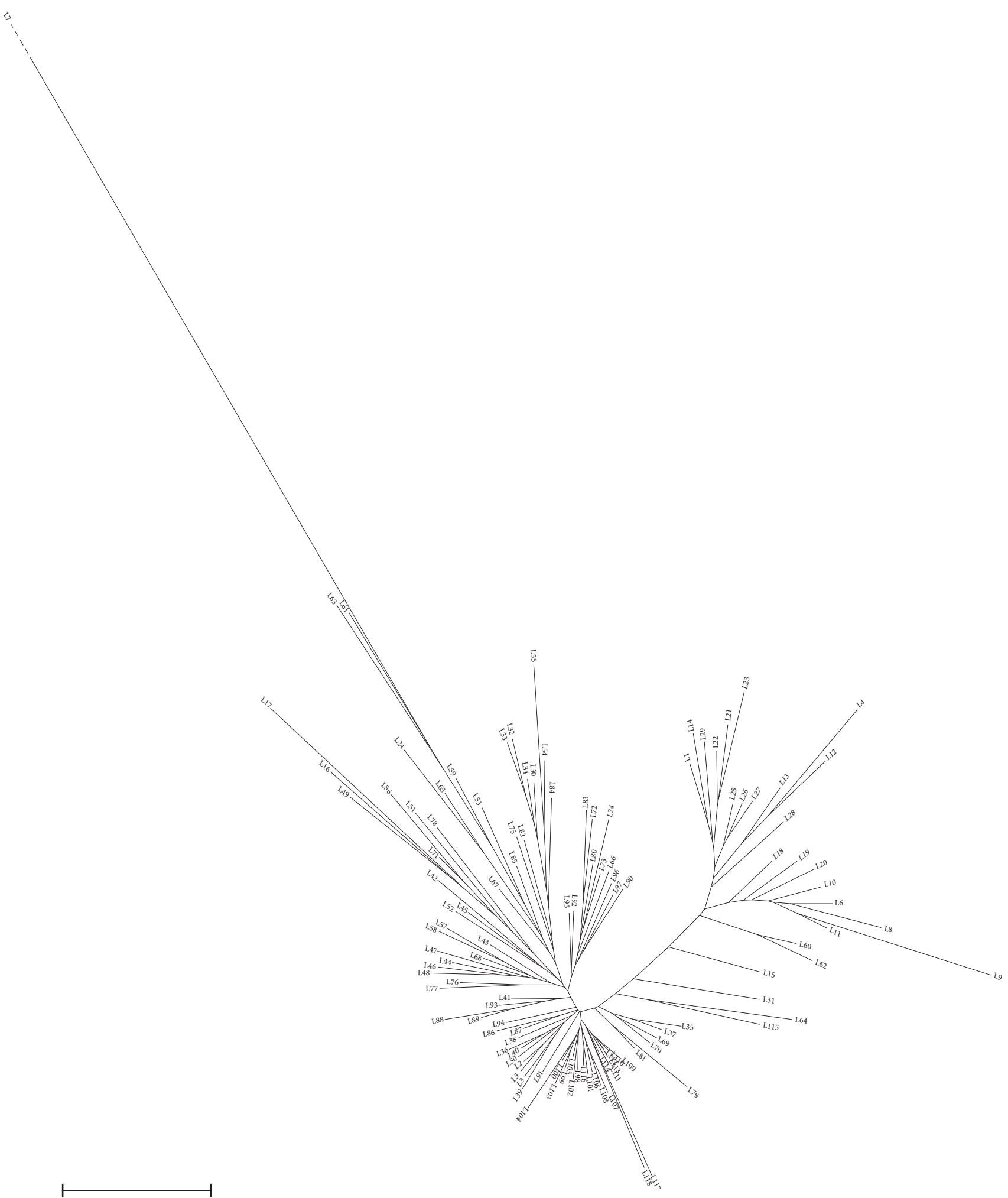

0.2

FIGURE 1: Neighbor-joining cluster of Ningmai 9 and its derivatives. Note: the genetic distance of L7 is so large that it is marked by dashed line. 
TABLE 2: The allele frequency between Ningmai 9 and its derivatives on chromosomes.

\begin{tabular}{|c|c|c|}
\hline \multirow{2}{*}{ Chromosome } & \multicolumn{2}{|c|}{ Allele frequency (\%) } \\
\hline & 1st generation & 2nd generation \\
\hline $1 \mathrm{~A}$ & 71.28 & 57.33 \\
\hline $2 \mathrm{~A}$ & 80.98 & 66.65 \\
\hline $3 \mathrm{~A}$ & 71.23 & 64.16 \\
\hline $4 \mathrm{~A}$ & 88.29 & 83.50 \\
\hline $5 \mathrm{~A}$ & 77.09 & 75.34 \\
\hline $6 \mathrm{~A}$ & 77.61 & 77.08 \\
\hline $7 \mathrm{~A}$ & 74.47 & 60.23 \\
\hline Mean & 77.28 & 69.18 \\
\hline $1 \mathrm{~B}$ & 68.61 & 61.01 \\
\hline $2 B$ & 73.08 & 70.61 \\
\hline $3 \mathrm{~B}$ & 79.40 & 72.37 \\
\hline $4 \mathrm{~B}$ & 76.71 & 64.02 \\
\hline $5 \mathrm{~B}$ & 79.39 & 67.69 \\
\hline $6 \mathrm{~B}$ & 69.97 & 62.60 \\
\hline $7 \mathrm{~B}$ & 80.14 & 73.98 \\
\hline Mean & 75.33 & 67.47 \\
\hline $1 \mathrm{D}$ & 75.30 & 66.54 \\
\hline $2 \mathrm{D}$ & 78.97 & 72.75 \\
\hline $3 \mathrm{D}$ & 64.86 & 56.33 \\
\hline $4 \mathrm{D}$ & 87.95 & 73.46 \\
\hline $5 \mathrm{D}$ & 72.49 & 64.24 \\
\hline $6 \mathrm{D}$ & 55.71 & 59.79 \\
\hline $7 \mathrm{D}$ & 84.09 & 74.27 \\
\hline Mean & 74.19 & 66.77 \\
\hline
\end{tabular}

Genome wide allele frequency

with Ningmai 9 (\%)

1st generation

75.60

2nd generation

67.81

mutant induced from hybrid seed treated with ${ }^{60}$ Co radiation.

3.3. Phenotype Analysis. There were significant variations among the derivatives of Ningmai 9 for all SRCs. The value of each SRC of the derivatives was higher, on average, than that of Ningmai 9, and the variations were high with coefficients of variation $(\mathrm{CV})$ ranging from 5.35\% in SuSRC (2014) to 8.63\% in WSRC (2015) (Table 3).

ANOVA revealed significant effects of genotype for all SRCs (Table 4). Year effect was also significant for SCSRC. ANOVA showed that the effect of genotype by year was not significant for each SRC. There was no significant difference among generations for SRCs except for SCSRC, though the values of all the SRCs in second generation were larger than that in first generation and in Ningmai 9 except for the value of LaSRC.

There was significant positive correlation between the two years for all SRCs (Table 5). The correlation between different SRCs was identical in the two years; SuSRC was significantly positively correlated with WSRC, SCSRC, and LaSRC, and there was also significant correlation between WSRC and SCSRC.

3.4. Association Analysis. A total of 29 markers on 13 wheat chromosomes were associated with the SRCs (Table 6). Five markers associated with WSRC were identified on chromosomes $4 \mathrm{~A}, 4 \mathrm{D}, 7 \mathrm{~B}$, and $7 \mathrm{D}, 21$ markers on chromosomes $1 \mathrm{~B}, 1 \mathrm{D}, 2 \mathrm{~A}, 2 \mathrm{~B}, 2 \mathrm{D}, 3 \mathrm{~B}, 4 \mathrm{~A}, 6 \mathrm{~A}, 6 \mathrm{~B}, 7 \mathrm{~A}, 7 \mathrm{~B}$, and $7 \mathrm{D}$ were associated with SCSRC, two markers on chromosome $3 \mathrm{~B}$ were associated with LaSRC, and four markers on chromosomes 1D, 2D, and 3B were associated with SuSRC. The QTL related to such markers could explain $5.12 \% \sim 12.05 \%$ of the phenotypic variation. Xgwm44 was associated with WSRC and SCSRC, and Xwmc754 and Xwmc326 were associated with both LaSRC and SuSRC. Xbarc126, Xwmc517, Xgwm484, $X w m c 754, X w m c 326$, and Xgwm232 were detected in both years, and $w m c 754$ and $w m c 326$ associated with LaSRC presented different alleles in two years. Most of the alleles of the marker associated with more than one SRC or detected in two years had negative effects on their corresponding SRCs, which were a benefit for soft wheat quality.

\section{Discussion}

Ningmai 9 is a soft wheat variety with stable soft wheat quality, high yield, wide adaptation, and resistance to multiple diseases including Fusarium head blight, soil born mosaic virus, and sharp eye spots released in 1997. Since 2006, 20 wheat cultivars derived from Ningmai 9 have been released to wheat production of the Yangtze River to the Huai River regions in China. As a founder parent, Ningmai 9 has a high general combining ability in sterile spikelet number (negative effect), grain weight per spike, protein content (negative effect), SRC (negative effect), and Fusarium head blight resistance, which means that it is easy to produce desirable traits in progenies [18]. At genomic level, founder parents have more favorable allelic variations than other varieties, and the genetic composition of new varieties is more similar to founder parent rather than the average value of parents. In this study, the genetic contribution of Ningmai 9 to its first and second generation was $75.60 \%$ and $67.81 \%$, respectively, which were both significantly higher than theoretical expectation of $50 \%$ and $25 \%$. The result was consistent with previous reports on other founder parents, such as Triumph/Yanda 1817 [28], Orofen [29], Bima 4 [30], and Zhou 8425B [31].

Solvent retention capacity (SRC) has been considered as an important breeding tool for predicting flour functionality of different wheat for different end uses ever since it has been developed [4, 32, 33]. SRC addresses the relative contributions to water absorption of each flour component using four different solvents: water, lactic acid, sodium carbonate, and 
TABLE 3: Phenotype variation for 4 SRCs of Ningmai 9 and its derivatives.

\begin{tabular}{llcccccc}
\hline Index & Year & Ningmai 9 & Mean & Stdev & Min & Max & CV (\%) \\
\hline \multirow{2}{*}{ WSRC } & 2014 & 59.49 & 64.03 & 5.36 & 49.43 & 79.40 & 8.37 \\
& 2015 & 59.60 & 63.72 & 5.50 & 49.98 & 77.25 & 8.63 \\
\multirow{2}{*}{ SCSRC } & 2014 & 78.96 & 86.73 & 6.86 & 71.11 & 98.91 & 7.91 \\
& 2015 & 79.85 & 85.66 & 6.97 & 70.38 & 100.15 & 8.13 \\
\multirow{2}{*}{ LaSRC } & 2014 & 108.52 & 116.88 & 9.24 & 93.98 & 141.71 & 7.91 \\
& 2015 & 109.05 & 117.23 & 9.57 & 96.21 & 146.57 & 8.16 \\
\multirow{3}{*}{ SuSRC } & 2014 & 108.85 & 116.05 & 5.97 & 99.15 & 131.09 & 5.15 \\
& 2015 & 109.51 & 117.06 & 6.45 & 104.39 & 132.75 \\
\hline
\end{tabular}

TABLE 4: ANOVA and multiple comparisons among generations for the SRCs of Ningmai 9 and its derivatives.

\begin{tabular}{lcccccc}
\hline \multirow{2}{*}{ Index } & \multicolumn{2}{c}{$F$ value } & & \multicolumn{2}{c}{ Multiple comparison test (S-N-K method) } \\
& Genotype & Year & Genotype $\times$ year & Ningmai 9 & 1st generation & 2 2nd generation \\
\hline WSRC & $5.24^{* *}$ & 0.52 & 0.28 & $59.55^{\mathrm{a}}$ & $61.15^{\mathrm{a}}$ & $65.29^{\mathrm{a}}$ \\
SCSRC & $8.04^{* *}$ & $6.02^{*}$ & 0.77 & $79.41^{\mathrm{a}}$ & $81.14^{\mathrm{ab}}$ & $88.81^{\mathrm{b}}$ \\
LaSRC & $4.75^{* *}$ & 0.21 & 0.54 & $108.79^{\mathrm{a}}$ & $117.72^{\mathrm{a}}$ & $116.83^{\mathrm{a}}$ \\
SuSRC & $3.43^{* *}$ & 3.00 & 0.51 & $109.18^{\mathrm{a}}$ & $115.66^{\mathrm{a}}$ & $117.10^{\mathrm{a}}$ \\
\hline
\end{tabular}

$* *$ and $*$ show significant difference at 0.01 and 0.5 level, respectively; different small letters in the same row show significant difference at 0.05 level.

TABLE 5: Correlation analysis for the SRCs over two years in Ningmai 9 and its derivatives.

\begin{tabular}{lcccc}
\hline & WSRC & SCSRC & LaSRC & SuSRC \\
\hline WSRC & $0.897^{* *}$ & $0.663^{* *}$ & -0.012 & $0.343^{* *}$ \\
SCSRC & $0.640^{* *}$ & $0.825^{* *}$ & -0.007 & $0.525^{* *}$ \\
LaSRC & 0.037 & 0.085 & $0.809^{* *}$ & $0.403^{* *}$ \\
SuSRC & $0.311^{* *}$ & $0.582^{* *}$ & $0.398^{* *}$ & $0.740^{* *}$ \\
\hline
\end{tabular}

$* *$ shows significant difference at 0.01 level. The correlation analysis for the same trait between 2014 and 2015 is marked on the diagonal; the correlation analysis among different traits in 2014 is marked below the diagonal, whereas the correlation analysis among different traits in 2015 is marked above.

sucrose. While WSRC has been associated with the overall water-holding capacity of all flour constituents, LaSRC is associated more specifically with the glutenin network formation and gluten elasticity or strength of flour. SCSRC is closely related to the amount of damaged starch of the flour, while SuSRC relates more specifically to the concentration of arabinoxylan and gliadin [19]. In this study, SRCs of Ningmai 9 and its derivatives were measured in two consecutive years, and all the SRCs of Ningmai 9 were lower than those of the derivatives on average, as wheat breeders did not take soft wheat as the only goal in wheat breeding. Therefore, genetic improvement for soft wheat quality would be strengthened in the future.

Identification of molecular marker associated with desired traits is a basis for marker assisted selection in wheat breeding. Association mapping is an effective method for identifying related markers. In this study, a total of 29 markers on 13 chromosomes were associated with the SRCs. Five markers associated with WSRC were identified on chromosomes 4A, 4D, 7B, and 7D. Cabrera et al. [9] and Carter et al. [34] discovered QTL related to WSRC on chromosomes $4 \mathrm{~A}$ and $4 \mathrm{D}$, respectively, and the QTL on $4 \mathrm{~A}$ was close to Xwmc468 detected in this study. Twenty-one markers on chromosomes $1 \mathrm{~B}, 1 \mathrm{D}, 2 \mathrm{~A}, 2 \mathrm{~B}, 2 \mathrm{D}, 3 \mathrm{~B}, 4 \mathrm{~A}, 6 \mathrm{~A}$, $6 \mathrm{~B}, 7 \mathrm{~A}, 7 \mathrm{~B}$, and $7 \mathrm{D}$ were associated with SCSRC in the study. Wmc751 on 3B reported by Carter et al. [34] was located at the interval between Xwmc777 and Xwmc653, and Xgwm44 on 7D was also reported by Zhang et al. [16]. Smith et al. (2011) found that a QTL on 2B associated with SCSRC was close to Xgwm257 by using 171 families from the cross Foster/Pioneer "25R26" [8]. Some markers on chromosomes $1 \mathrm{~A}, 1 \mathrm{~B}, 3 \mathrm{~A}, 3 \mathrm{~B}, 6 \mathrm{~A}$, and $7 \mathrm{~A}$ related to SCSRC were also reported $[8,9,16]$, but a little far from the ones we detected, as the markers on multiple chromosomes including chromosomes 1D, 2D, and 3B associated with LaSRC and SuSRC. There was high correlation between two years for all SRCs, but only a few markers were repeatedly detected, which might be due to a limited number of markers used in this study. The association mapping in Ningmai 9 and its derivatives showed that SRCs were determined by lots of minor QTL effects but also the environment, which suggest that the genetic mechanism of SRCs was complex in Ningmai 9 and QTL controlling SRCs might differ from other varieties. The favorable allelic variations of Xgwm44, Xbarc126, Xwmc790, and Xgwm232 associated with SRCs in Ningmai 9 may be used for quality improvement in soft wheat breeding.

\section{Competing Interests}

The authors declare that they have no competing interests. 
TABLE 6: Association analysis for SRCs.

\begin{tabular}{|c|c|c|c|c|c|c|c|c|}
\hline \multirow{2}{*}{ Traits } & \multirow{2}{*}{ Marker } & \multirow{2}{*}{ Chromosome } & \multicolumn{3}{|c|}{2014} & \multicolumn{3}{|c|}{2015} \\
\hline & & & $P$ & $R^{2}(\%)$ & Effect (allele) & $P$ & $R^{2}(\%)$ & Effect (allele) \\
\hline \multirow{5}{*}{ WSRC } & Xwmc468 & $4 \mathrm{AL}$ & $4.74 \times 10^{-3}$ & 6.61 & $-(134)$ & & & \\
\hline & Xwmc89 & $4 \mathrm{DS}$ & $8.10 \times 10^{-3}$ & 5.94 & $-(140)$ & & & \\
\hline & $X w m c 517$ & $7 \mathrm{BL}$ & & & & $9.68 \times 10^{-3}$ & 5.71 & $+(183)$ \\
\hline & Xgwm44 & 7DS & $8.11 \times 10^{-3}$ & 5.78 & $-(196)$ & $1.37 \times 10^{-3}$ & 8.84 & $-(196)$ \\
\hline & Xbarc126 & 7DS & $6.48 \times 10^{-3}$ & 6.13 & $-(170)$ & $4.34 \times 10^{-4}$ & 10.80 & $-(170)$ \\
\hline \multirow{21}{*}{ SCSRC } & Xgwm153 & $1 \mathrm{BL}$ & & & & $5.65 \times 10^{-3}$ & 6.02 & $-(188)$ \\
\hline & $X c f d 72$ & $1 \mathrm{DL}$ & & & & $4.55 \times 10^{-3}$ & 6.22 & $+(310)$ \\
\hline & $X g w m 232$ & $1 \mathrm{DL}$ & $7.64 \times 10^{-4}$ & 8.57 & $+(144)$ & & & \\
\hline & Xwmc658 & $2 \mathrm{AL}$ & $6.82 \times 10^{-3}$ & 5.44 & $+(250)$ & & & \\
\hline & $X g w m 257$ & $2 \mathrm{BS}$ & & & & $9.54 \times 10^{-3}$ & 5.16 & $-(186)$ \\
\hline & Xgwm539 & $2 \mathrm{DL}$ & $6.32 \times 10^{-3}$ & 5.56 & $+(160)$ & & & \\
\hline & Xgwm102 & 2DS & $3.04 \times 10^{-3}$ & 6.57 & $+(142)$ & & & \\
\hline & Xgwm484 & 2DS & $1.94 \times 10^{-4}$ & 10.81 & $-(179)$ & $2.90 \times 10^{-3}$ & 6.96 & $-(179)$ \\
\hline & $X w m c 231$ & $3 \mathrm{~B}$ & $1.09 \times 10^{-3}$ & 8.17 & $+(240)$ & & & \\
\hline & $X w m c 777$ & $3 \mathrm{~B}$ & $4.13 \times 10^{-4}$ & 9.48 & $-(100)$ & & & \\
\hline & $X w m c 653$ & $3 \mathrm{~B}$ & & & & $6.05 \times 10^{-3}$ & 5.83 & $-(160)$ \\
\hline & $X w m c 219$ & $4 \mathrm{AL}$ & $6.68 \times 10^{-3}$ & 5.47 & $+(160)$ & & & \\
\hline & Xgwm169 & $6 \mathrm{AL}$ & & & & $9.54 \times 10^{-3}$ & 5.68 & $-(190)$ \\
\hline & $X w m c 397$ & $6 \mathrm{BL}$ & $9.68 \times 10^{-5}$ & 12.05 & - & & & \\
\hline & Xwmc790 & $7 \mathrm{~A}$ & $1.68 \times 10^{-3}$ & 7.42 & $-(108)$ & & & \\
\hline & Xwmc809 & $7 \mathrm{~A}$ & & & & $6.04 \times 10^{-3}$ & 5.81 & $-(180)$ \\
\hline & $X w m c 311$ & $7 \mathrm{BL}$ & $9.64 \times 10^{-3}$ & 5.12 & $+(120)$ & & & \\
\hline & Xwmc634 & $7 \mathrm{DL}$ & $4.16 \times 10^{-4}$ & 10.17 & $+(210)$ & & & \\
\hline & Xgwm437 & $7 \mathrm{DL}$ & & & & $6.04 \times 10^{-3}$ & 5.81 & $-(110)$ \\
\hline & Xgwm44 & 7DS & & & & $6.61 \times 10^{-3}$ & 5.88 & $-(183)$ \\
\hline & $X c f d 14$ & 7DS & & & & $1.80 \times 10^{-3}$ & 7.62 & $-(100)$ \\
\hline \multirow{2}{*}{ LaSRC } & $X w m c 754$ & $3 \mathrm{~B}$ & $2.09 \times 10^{-3}$ & 8.77 & $-(160)$ & $7.89 \times 10^{-3}$ & 6.39 & $+(152)$ \\
\hline & Xwmc326 & $3 \mathrm{~B}$ & $7.20 \times 10^{-3}$ & 7.15 & $+(186)$ & $8.29 \times 10^{-3}$ & 7.00 & $+(186)$ \\
\hline \multirow{4}{*}{ SuSRC } & $X g w m 232$ & $1 \mathrm{DL}$ & $5.17 \times 10^{-4}$ & 10.44 & $-(144)$ & $4.27 \times 10^{-3}$ & 7.20 & $-(144)$ \\
\hline & Xgwm349 & $2 \mathrm{DL}$ & $5.97 \times 10^{-3}$ & 6.47 & $+(310)$ & & & \\
\hline & $X w m c 754$ & $3 \mathrm{~B}$ & $5.96 \times 10^{-3}$ & 6.68 & $-(160)$ & & & \\
\hline & Xwmc326 & $3 \mathrm{~B}$ & & & & $4.38 \times 10^{-3}$ & 7.35 & $+(186)$ \\
\hline
\end{tabular}

The number in brackets following "+" or "-" represents the allele of markers, and "+" and "-" indicate a positive or negative effect by the allele of markers.

\section{Acknowledgments}

This work was partially supported by the national key project for the research and development of China (2016YFD0100500) and the indigenous innovation foundation of Jiangsu provincial agricultural science and technology (CX[14]2002), China Agricultural Research System Program (CARS-03).

\section{References}

[1] M. Moiraghi, L. Vanzetti, C. Bainotti, M. Helguera, A. León, and G. Pérez, "Relationship between Soft wheat flour physicochemical composition and cookie-making performance," Cereal Chemistry, vol. 88, no. 2, pp. 130-136, 2011.

[2] A. Abboud, R. C. Hoseney, and G. Rubenthater, "Effect of fat and sugar in sugar-snap cookies and evaluation of tests to measure cookie flour quality," Cereal Chemistry Journal, vol. 62, pp. 124129, 1985.

[3] M. Kweon, L. Slade, and H. Levine, "Solvent retention capacity (SRC) testing of wheat flour: principles and value in predicting flour functionality in different wheat-based food processes and in wheat breeding-a review," Cereal Chemistry, vol. 88, no. 6, pp. 537-552, 2011.

[4] L. Slade and H. Levine, "Structure-function relationships of cookie and cracker ingredients," Cereal Chemistry Journal, vol. 81, pp. 261-266, 1994.

[5] M. J. Guttieri, D. Bowen, D. Gannon, K. O’Brien, and E. Souza, "Solvent retention capacities of irrigated soft white spring wheat flours," Crop Science, vol. 41, no. 4, pp. 1054-1061, 2001.

[6] M. J. Guttieri and E. Souza, "Sources of variation in the solvent retention capacity test of wheat flour," Crop Science, vol. 43, no. 5, pp. 1628-1633, 2003. 
[7] Q. J. Zhang, Y. Zhang, Z. H. He, and R. J. Pena, "Relationship between soft wheat quality traits and cookie quality parameters," Acta Agronomica Sinica, vol. 31, no. 9, pp. 1125-1131, 2005.

[8] N. Smith, M. Guttieri, E. Souza, J. Shoots, M. Sorrells, and C. Sneller, "Identification and validation of QTL for grain quality traits in a cross of soft wheat cultivars pioneer brand $25 \mathrm{r} 26$ and foster," Crop Science, vol. 51, no. 4, pp. 1424-1436, 2011.

[9] A. Cabrera, M. Guttieri, N. Smith et al., "Identification of milling and baking quality QTL in multiple soft wheat mapping populations," Theoretical and Applied Genetics, vol. 128, no. 11, pp. 2227-2242, 2015.

[10] S. A. Flint-Garcia, J. M. Thornsberry, and E. S. Buckler, "Structure of linkage disequilibrium in plants," Annual Review of Plant Biology, vol. 54, pp. 357-374, 2003.

[11] J. R. Andersen, T. Schrag, A. E. Melchinger, I. Zein, and T. Lübberstedt, "Validation of Dwarf8 polymorphisms associated with flowering time in elite European inbred lines of maize (Zea mays L.)," Theoretical and Applied Genetics, vol. 111, no. 2, pp. 206-217, 2005.

[12] F. Breseghello and M. E. Sorrells, "Association mapping of kernel size and milling quality in wheat (Triticum aestivum L.) cultivars," Genetics, vol. 172, no. 2, pp. 1165-1177, 2006.

[13] H. A. Agrama, G. C. Eizenga, and W. Yan, "Association mapping of yield and its components in rice cultivars," Molecular Breeding, vol. 19, no. 4, pp. 341-356, 2007.

[14] J. Bordes, C. Ravel, J. Le Gouis, A. Lapierre, G. Charmet, and F. Balfourier, "Use of a global wheat core collection for association analysis of flour and dough quality traits," Journal of Cereal Science, vol. 54, no. 1, pp. 137-147, 2011.

[15] J. C. Reif, M. Gowda, H. P. Maurer et al., "Association mapping for quality traits in soft winter wheat," Theoretical and Applied Genetics, vol. 122, no. 5, pp. 961-970, 2011.

[16] Y. Zhang, X. Zhang, J. Guo, D. Gao, and B. Zhang, "Association analysis of solvent retention capacity in soft wheat," Acta Agronomica Sinica, vol. 41, no. 2, pp. 251-258, 2015.

[17] X. Y. Zhang, Y. P. Tong, G. X. You et al., "Hitchhiking effect mapping: a new approach for discovering agronomic important genes," Scientia Agricultura Sinica, vol. 39, pp. 1526-1535, 2006.

[18] J. B. Yao, H. X. Ma, P. P. Zhang et al., "Research of wheat elite parent Ningmai 9 and its utilization," Acta Agriculturae Nucleatae Sinica, vol. 26, pp. 17-21, 2012.

[19] C. Gaines, "Report of the AACC committee on soft wheat flour. Method 56-11, solvent retention capacity profile," Cereal Foods World, vol. 45, pp. 303-306, 2000.

[20] L. C. Haynes, A. D. Bettge, and L. Slade, "Soft wheat and flour products methods review: solvent retention capacity equation correction," Cereal Foods World, vol. 54, no. 4, pp. 174-175, 2009.

[21] M. A. Saghai-Maroof, K. M. Soliman, R. A. Jorgensen, and R. W. Allard, "Ribosomal DNA spacer-length polymorphisms in barley: mendelian inheritance, chromosomal location, and population dynamics," Proceedings of the National Academy of Sciences of the United States of America, vol. 81, no. 24, pp. 80148018, 1984.

[22] D. J. Somers, P. Isaac, and K. Edwards, "A high-density microsatellite consensus map for bread wheat (Triticum aestivum L.)," Theoretical and Applied Genetics, vol. 109, no. 6, pp. 1105-1114, 2004.

[23] K. Tamura, G. Stecher, D. Peterson, A. Filipski, and S. Kumar, "MEGA6: molecular evolutionary genetics analysis version 6.0," Molecular Biology and Evolution, vol. 30, no. 12, pp. 2725-2729, 2013.
[24] M. J. Hubisz, D. Falush, M. Stephens, and J. K. Pritchard, "Inferring weak population structure with the assistance of sample group information," Molecular Ecology Resources, vol. 9, no. 5, pp. 1322-1332, 2009.

[25] P. J. Bradbury, Z. Zhang, D. E. Kroon, T. M. Casstevens, Y. Ramdoss, and E. S. Buckler, "TASSEL: software for association mapping of complex traits in diverse samples," Bioinformatics, vol. 23, no. 19, pp. 2633-2635, 2007.

[26] G. Evanno, S. Regnaut, and J. Goudet, "Detecting the number of clusters of individuals using the software STRUCTURE: a simulation study," Molecular Ecology, vol. 14, no. 8, pp. 26112620, 2005.

[27] P. Jiang, P.-P. Zhang, X. Zhang, X. Chen, and H.-X. Ma, "Association analysis for mixograph properties in Ningmai 9 and its deriva-tives," Acta Agronomica Sinica, vol. 42, no. 8, pp. 1168-1175, 2016.

[28] J. Han, L. Zhang, J. Li et al., "Molecular dissection of core parental cross "Triumph/Yanda1817" and its derivatives in wheat breeding program," Acta Agronomica Sinica, vol. 35, no. 8, pp. 1395-1404, 2009.

[29] X. J. Li, X. Xu, W. H. Liu, X. Q. Li, and L. H. Li, "Genetic diversity of the founder parent Orofen and its progenies revealed by SSR markers," Scientia Agricultura Sinica, vol. 42, pp. 3397-3404, 2009.

[30] Y.-Y. Yuan, Q.-Z. Wang, F. Cui, J.-T. Zhang, B. Du, and H.G. Wang, "Specific loci in genome of wheat milestone parent bima 4 and their transmission in derivatives," Acta Agronomica Sinica, vol. 36, no. 1, pp. 9-16, 2010.

[31] Y. G. Xiao, G. H. Yin, H. H. Li et al., "Genetic diversity and genome-wide association analysis of stripe rust resistance among the core wheat parent zhou $8425 \mathrm{~b}$ and its derivatives," Scientia Agricultura Sinica, vol. 44, pp. 3919-3929, 2011.

[32] A. Colombo, G. T. Pérez, P. D. Ribotta, and A. E. León, "A comparative study of physicochemical tests for quality prediction of Argentine wheat flours used as corrector flours and for cookie production," Journal of Cereal Science, vol. 48, no. 3, pp. 775-780, 2008.

[33] C. Guzmán, G. Posadas-Romano, N. Hernández-Espinosa, A. Morales-Dorantes, and R. J. Peña, "A new standard water absorption criteria based on solvent retention capacity (SRC) to determine dough mixing properties, viscoelasticity, and breadmaking quality," Journal of Cereal Science, vol. 66, pp. 59-65, 2015.

[34] A. H. Carter, K. Garland-Campbell, and K. K. Kidwell, "Genetic mapping of quantitative trait loci associated with important agronomic traits in the spring wheat (Triticum aestivum L.) Cross "Louise" × "Penawawa"," Crop Science, vol. 51, no. 1, pp. 84-95, 2011. 

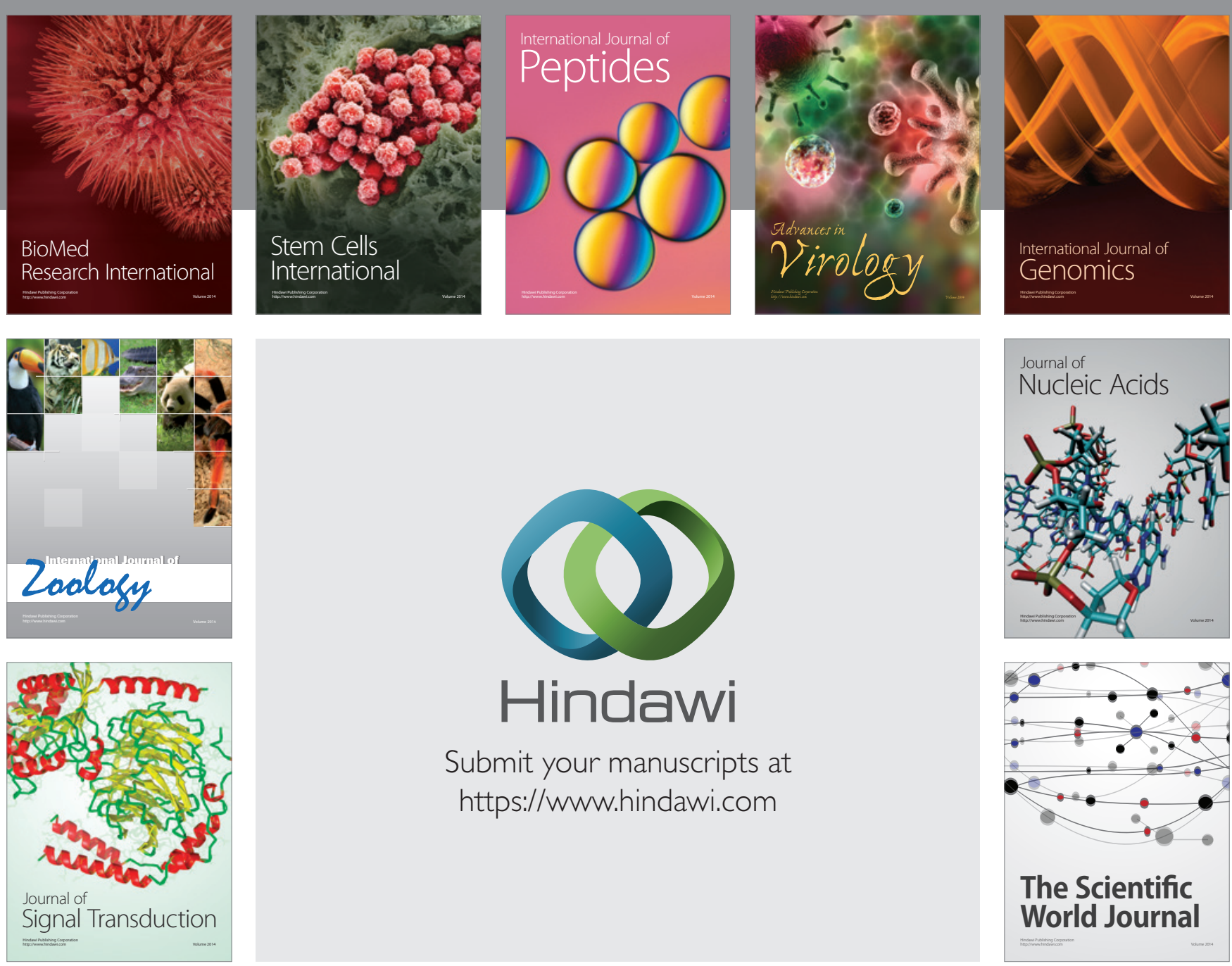

Submit your manuscripts at

https://www.hindawi.com
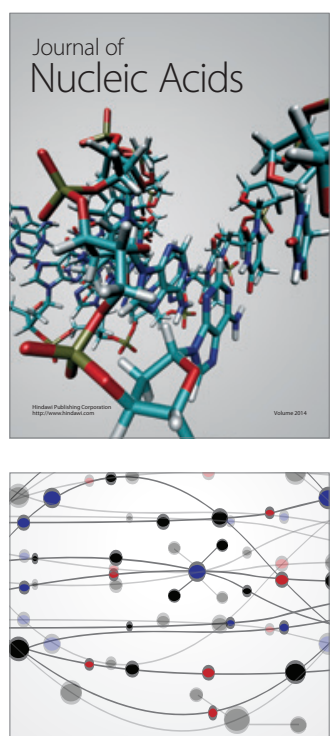

The Scientific World Journal
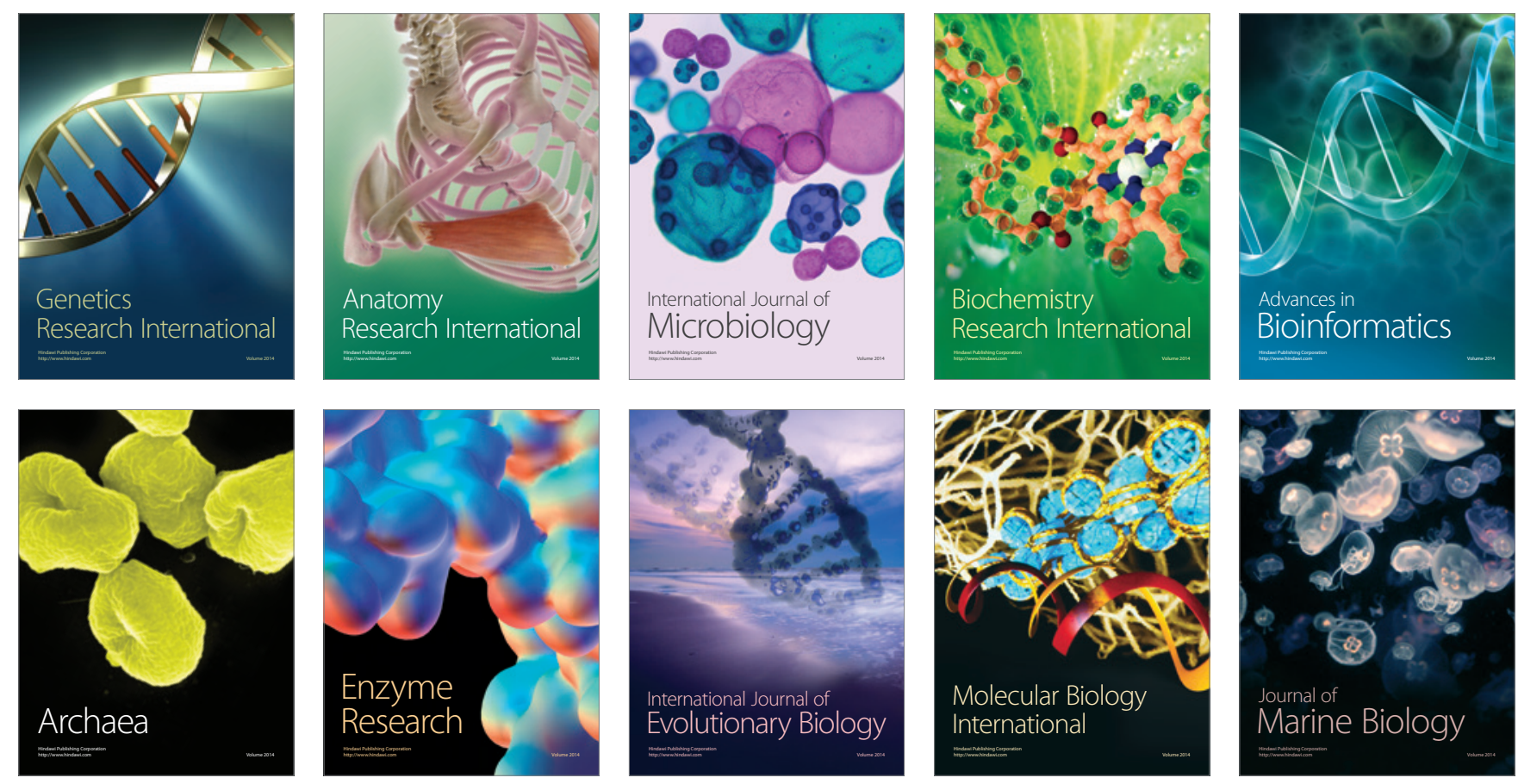